\title{
A new process for the rapid and direct vermicomposting of the aquatic weed salvinia (Salvinia molesta)
}

T Ganeshkumar, M Premalatha, S Gajalakshmi* and SA Abbasi

\begin{abstract}
Background: The concept of high-rate vermicomposting was successfully used to achieve direct vermicomposting of the aquatic weed salvinia - without any precomposting or cow dung supplementation as previously reported processes for the vermicomposting of phytomass had necessitated.

Results: Both the epigeic species of earthworms that were explored, Eudrilus eugeniae and Eisenia fetida, provided efficient vermicast production with no mortality, persistent gain in body mass, and good fecundity over the 270day-long course of the reactor operation. In this period, all reactors were pulse-fed at the solid retention time of 15 days and were operated in the pseudo-discretized continuous operation protocol developed earlier by the authors. With this, it was possible to almost completely dampen the influence of natural biodegradation of the feed or grazing by the earthworm born in the vermireactors. This has made it possible to link vermicast production directly to the ability of the earthworm to feed upon, and digest, salvinia. In turn, this enables accurate process monitoring and provides clear pointers on how to improve process efficiency.

Conclusion: The paper establishes the capability of high-rate vermicomposting technology developed earlier by the authors in direct and efficient vermicomposting of salvinia without any precomposting or manure supplementation. The findings have very significant implications in improving process economics and consequently process utility. No previous report exists in primary literature on the vermicomposting of salvinia.
\end{abstract}

\section{Background}

Salvinia (Salvinia molesta D. S. Mitchell) is a freefloating aquatic weed, native to South Africa [1]. It is capable of sexual as well as vegetative reproduction and is known for its explosive growth rate. There are instances on record where a few salvinia plants have multiplied so rapidly that even lakes as large as Lake Kariba, with a water-spread of $100 \mathrm{~km}^{2}$, have been covered by the plant's dense mats in a matter of a few weeks $[2,3]$. During the last five decades, salvinia has invaded many tropical and subtropical countries of Asia, Africa, and the Pacific regions. It has become a scourge of wetlands, eroding their water-storage space, jeopardizing their water quality, and harming their biodiversity $[4,5]$. The debris of dead leaves and plants of salvinia undergoes aerobic or anaerobic biodegradation - depending on whether the

\footnotetext{
* Correspondence: dr.s.gajalakshmi@gmail.com

Centre for Pollution Control and Environmental Engineering, Pondicherry University, Kalapet, Puducherry 605014, India
}

decomposition occurs in aerobic or anoxic zones of the wetland - generating global warming gases $\mathrm{CO}_{2}$ and $\mathrm{CH}_{4}$ [6]. In this manner, colonization of wetlands by salvinia is a major cause of eco-degradation and global warming.

Attempts have been made from time to time to find a use for salvinia as a bioagent for wastewater treatment; as a mulch/fertilizer/animal feed/adsorbent; as raw material for handicraft, paper, chemicals, or biogas; and for nanoparticles synthesis [7-10]. However, none of these potential uses except the one in wastewater treatment have proved economically viable. Moreover, use of salvinia in this manner still leaves the problem of its disposal unsolved.

In recent years, Abbasi and coworkers have introduced the concept of high-rate vermicomposting and have developed associated technology [11-17], which enables direct and efficient vermicomposting of phytomass. As has been

\section{实}

(c) 2014 Ganeshkumar et al.; licensee Springer. This is an Open Access article distributed under the terms of the Creative Commons Attribution License (http://creativecommons.org/licenses/by/4.0), which permits unrestricted use, distribution, and reproduction in any medium, provided the original work is properly credited. 
reviewed recently $[18,19]$, the use of phytomass as a substrate for generating vermicompost had been very limited prior to the introduction of this know-how and no methods had existed on vermicomposting of phytomass which had the potential for large-scale utilization. This was due to the following reasons:

a) All the past attempts have depended on supplementing the phytomass with large proportions of animal manure, especially cow dung $[13,15,18,19]$. This has two major disadvantages. First is that to process the very large quantities of phytomass that are available, equally large quantities of animal manure shall be needed. But it is not easy to find so much manure because of numerous competitive uses already in existence $[20,21]$. The second major disadvantage is that, unlike waste phytomass, animal manure is not available free of cost [21]. Hence dependence on animal manure makes the process economics highly unfavorable.

b) The reported processes have all been very slow, taking 2 months or more to achieve substantial conversion of phytomass to vermicast (unless precomposting had been done). As the rate of any process is directly related to its efficiency, hence economics, this aspect further diminishes the utilizability of the reported processes [18].

c) When precomposting had to be done, it further adds time and cost to the overall process, eroding its economic viability still further [19].

The present paper reports the successful application of the high-rate vermicomposting technology in achieving direct and rapid vermicomposting of salvinia. Two epigeic earthworm species - Eudrilus eugeniae and Eisenia fetida - which are well-known for their ability to vermicompost animal manure [22-24], were explored and were found to be highly successful in utilizing salvinia as well. No previous report exists in primary literature on the vermicomposting of salvinia.

\section{Methods}

Fresh whole plants of salvinia, which are about 1-ft long if measured from tip to toe, were collected from the ponds situated near the Pondicherry University campus. The plants were washed thoroughly to remove adhering soil particles and lightly wiped before subjecting them to vermicomposting.

Circular 7-L plastic containers (diameter $16 \mathrm{~cm}$, effective height $12 \mathrm{~cm}$ ) were used as vermireactors. The reactors were lined with plastic material to prevent worms from escaping and predation. Jute cloth sheets of 3-mm thickness saturated with water were placed at the bottom of each reactor, and the feed, in the form of $3 \mathrm{~kg}$ of salvinia (dry weight $250 \mathrm{~g}$ ), was laid over it. The reactors were operated in the pseudo-discretized continuous reactor operation (PDCOP) mode as described earlier by the authors ([22,25]; Sankar [14]); PDCOP enables an operation which is not really continuous but creates an ambience of a continuous reactor operation. In it, the reactors are started with a certain fixed quantity of substrate and population of adult earthworm. After 15 or 20 days, the contents are removed and the extent of conversion of the substrate to vermicast, change of zoomass of the adult earthworms, and fecundity (in terms of number of juveniles and cocoons generated) are quantified. Within minutes, the reactors are restarted with fresh substrate and the same adult earthworms that were employed initially. In this way, it is possible to record the rate of vermicast production per adult earthworm as a function of time. By removing unconsumed substrate which would otherwise biodegrade even without the action of the earthworms - the impact of happenings other than ingestion by the earthworms is minimized. Also, the earthworms are always grazing upon totally fresh, or nearly fresh, substrate as they would have in a truly continuous vermireactor. Additionally, since the juveniles that are produced are removed before they grow significantly big to consume significant quantities of substrate, it is possible to dampen their influence on the reactor performance as well.

In the present work, the reactors were started by introducing in them 250 healthy, adult individuals of either E. fetida or E. eugeniae, picked randomly from cow-dung-fed cultures maintained by the authors. Once every 15 days, the reactor contents were removed and placed in a separate container for the quantification of vermicast, zoomass change in adults, and production of juveniles and cocoons. Within a few minutes, fresh reactors were started with everything else the same as at the start except that from the earthworms removed from the previous run, only the adults were reintroduced into the reactor. All treatments were done in triplicate.

During the course of the experiments, the reactors were kept under the same ambient conditions of $30^{\circ} \mathrm{C} \pm 4^{\circ} \mathrm{C}$ temperature and $60 \% \pm 10 \%$ relative humidity. Their water content was maintained in the range $60 \%$ to $70 \%$. All quantities were adjusted so that the feed and the casting mass reported in this paper represent dry weights (taken after oven-drying at $105^{\circ} \mathrm{C}$ to constant weight). The earthworm biomass is reported as live weight, taken after rinsing adhering material of the worms and blotting them dry. The castings were sieved through a $3-\mathrm{mm}$ mesh to separate other particles. In this manner, it was possible to assess the vermicast output of 'parent' worms as a function of $1 \mathrm{~kg}$ of feed, without competition from offspring. It also ensured that the unutilized feed did not accumulate, and possibly biodegrade, in the reactors. 


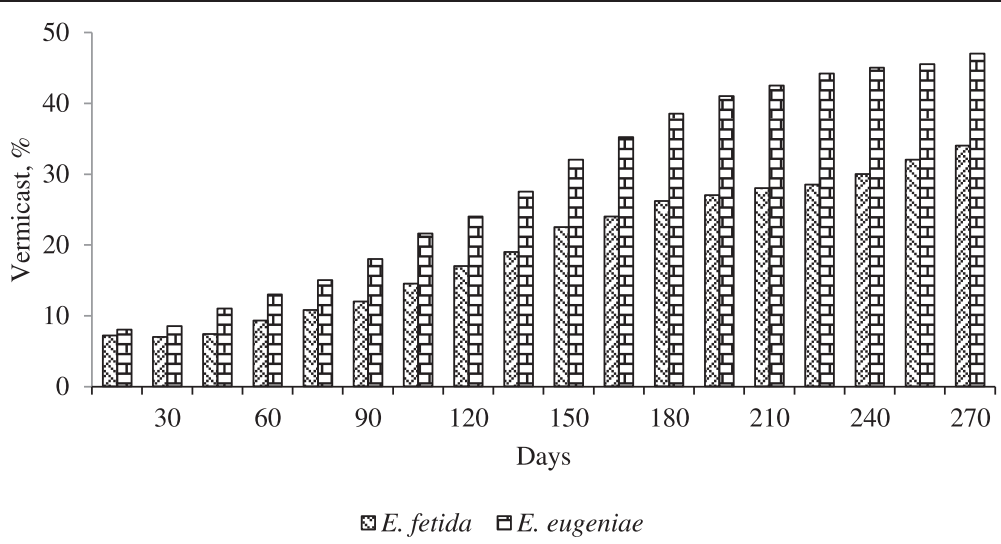

Figure 1 Vermicast generated, as a percentage of feed mass in reactors operated with E. fetida and E. eugeniae.

\section{Results and discussion}

The reactors were operated for 270 days ( 9 months) and appeared set to go on indefinitely when the experiment was terminated. The extent of vermicast production, in terms of fraction of the feed converted to vermicast, is summarized in Figure 1. Median value of the reactors operated in triplicate have been given, the agreement between the replicates was within a relative error of $\pm 10 \%$ which indicates good reproducibility given the heterogeneous nature of the reactor content and natural variability in the feed characteristics.

As is seen in Figure 1, less than $10 \%$ of the feed was vermicomposted during the first 30 days. Then the rate began to increase steadily and crossed $40 \%$ in the reactors with $E$. eugeniae and $27 \%$ in the reactor with E. fetida by the 13th run ( $6 \frac{1}{2}$ months of reactor operation). The difference in per capita vermicast output between E. fetida and $E$. eugeniae was not statistically significant till the 75 th day. Thereafter, it became significant at $\geq 95 \%$ confidence level as revealed by Student's $t$-test. The rate of vermicast generation continued to increase even after the 13th run but much slowly. The pattern of change in the rate of vermicast production with time is seen to approximately follow a sigmoid pattern - an initial lag phase (30 days), followed by rapid increase during the next 165 days, and a mildly increasing trend thereafter. As the earthworms had been reared on cow dung as the sole feed, upon transfer to vermireactors which had a feed of totally different texture and taste, there might have been an initial sluggishness in feeding. As the animals got acclimated to the new feed as well as the new type of confinements in the vermireactors, their feeding activity picked up. As may be seen from Table 1, the animals steadily gained weight from the 30th day onwards after a zero or negligible weight gain in the first 30 days. The fecundity also increased with time as is reflected in the steady rise in the average number of juveniles produced by the two species in their respective vermireactors (Figure 2). The trend in the vermiconversion-time curve of Figure 1 indicates that the rate of conversion of salvinia to vermicast was approaching $50 \%$ and $35 \%$ per fortnight in reactors operated with E. fetida. This amounts to $100 \%$ conversion in 30 and 45 days, respectively, for the two species. Had the juveniles produced during the first 120 days not been removed as we have done, the rate of

Table 1 Increase in earthworm zoomass with time

\begin{tabular}{lccccc}
\hline & \multicolumn{2}{c}{ E. fetida } & & \multicolumn{2}{c}{ E. eugeniae } \\
\cline { 2 - 3 } \cline { 5 - 6 } $\begin{array}{c}\text { Zoomass, g, } \\
\text { of } \mathbf{2 5 0} \text { adults }\end{array}$ & $\begin{array}{c}\text { Increase with } \\
\text { respect to } \\
\text { initial mass, \% }\end{array}$ & $\begin{array}{c}\text { Zoomass, g, } \\
\text { of } \mathbf{2 5 0} \text { adults }\end{array}$ & $\begin{array}{c}\text { Increase with } \\
\text { respect to } \\
\text { initial mass, \% }\end{array}$ \\
\hline 0 & 112.1 & 0 & & 134.3 & 0 \\
15 & 112.3 & 0.2 & & 134.3 & 0 \\
30 & 112.8 & 0.6 & & 135.3 & 0.7 \\
45 & 113 & 0.8 & & 136.6 & 1.7 \\
60 & 113.9 & 1.6 & & 137.9 & 2.7 \\
75 & 114.8 & 2.4 & & 139.2 & 3.6 \\
90 & 116 & 3.5 & & 140.8 & 4.8 \\
105 & 117.1 & 4.5 & & 142.3 & 6.0 \\
120 & 118.2 & 5.4 & & 143.8 & 7.0 \\
135 & 119.3 & 6.4 & & 145.3 & 8.2 \\
150 & 120.1 & 7.1 & & 146.6 & 9.2 \\
165 & 121.3 & 8.2 & & 148.5 & 10.6 \\
180 & 122.5 & 9.3 & & 150.7 & 12.2 \\
195 & 124 & 10.6 & 152.6 & 13.6 \\
210 & 125.2 & 11.7 & 154.9 & 15.3 \\
225 & 126.7 & 13.0 & 156.7 & 16.7 \\
240 & 127.9 & 14.1 & & 158.9 & 18.3 \\
255 & 129.1 & 15.2 & & 160.8 & 19.7 \\
270 & 130.8 & 16.7 & & 163.3 & 21.6 \\
\hline
\end{tabular}




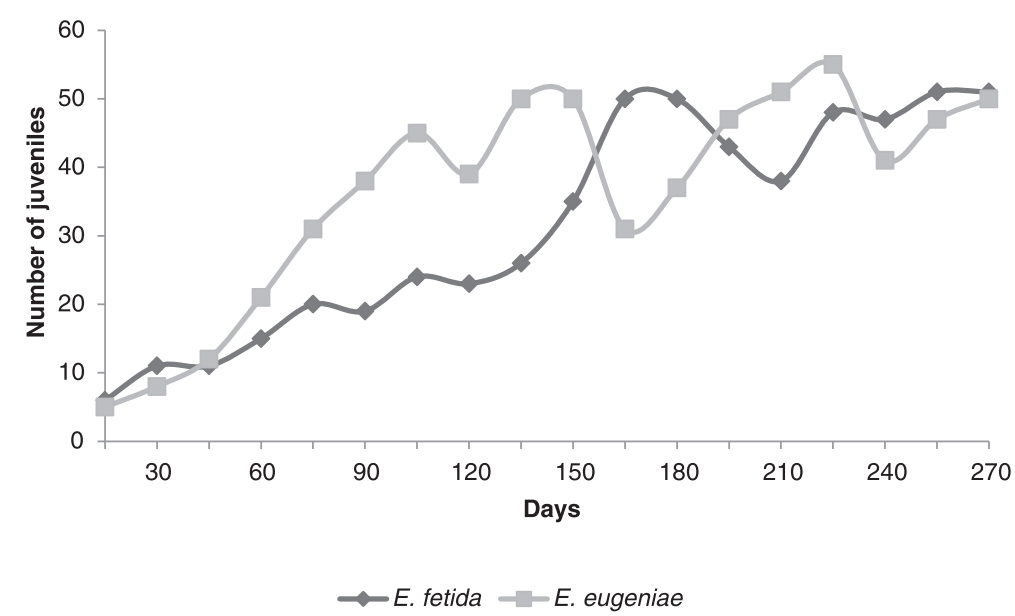

Figure 2 Juveniles produced in vermireactors operated with E. fetida and E. eugeniae. AJ5 Salvinia molesta 31.5.14_3.

vermiconversion would have been much higher by the 270th day as, by then, the offspring produced during the first few months would have reached adulthood and caused a much higher rate-of-feed utilization. Indeed, given the high rate of juvenile production, which averaged 2.1 and 2.4 individuals per day in E. fetida and E. eugeniae, respectively (Figure 2), the rate of feed utilization is likely to have been near quantitative at the 15-day SRT had the offspring been retained in the reactor.

Even though, on an average, each adult of E. eugeniae was generating about $15 \%$ more vermicast than each individual of $E$. fetida, on a unit zoomass basis, the latter was nearly as efficient a vermicomposter as the former - both animals generating about $0.7 \mathrm{~g}$ of vermicast per gram of body weight towards the closing stages of the experiment.

The results also indicate that if the reactors are operated in a normal pulse-fed fashion, wherein some feed biodegradation will occur naturally as well as earthworms born in the reactors will hasten feed utilization, it may be possible to achieve near $100 \%$ process efficiency at solid retention times of 15 to 20 days. Given that conventional vermicomposting requires 3 to 4 months for complete feed conversion, this may amount to a threefold to fourfold gain in process efficiency and consequently in process economics. Indeed, the rate of vermicast production can be increased further by employing a larger number of earthworms from the outset - up to a limit that has been defined by us earlier as the "highest sustainable earthworm density' $[11,13]$. Hence the process efficiency can be made substantially higher than achieved in the experiments.

Ongoing, yet-to-be-published, studies on the effect of salvinia vermicast on the germination and growth of botanical plants, in comparison to chemical fertilizers of identical macronutrient and micronutrient content, have revealed that salvinia vermicast is a superior fertilizer.
This is possibly due to the presence of plant-friendly enzymes and hormones that vermicast, in general, are known to possess [24].

\section{Conclusions}

Whole plants of the aquatic weed salvinia (S. molesta) were directly vermicomposted - without precomposting or any other form of elaborate pretreatment and without any fortification with animal manure - by the application of the concept of high-rate vermicomposting developed earlier by the authors. With it, vermireactors were operated, separately, with two common earthworm species E. fetida or E. eugeniae for 270 days. The PDCOP earlier developed by the authors was used to assess the efficiency of the conversion of the feed to vermicast in a manner that almost completely dampened the possible effect of the natural biodegradation of the feed. PDCOP similarly dampened the contribution of the earthworms that were born in the reactors on the process. With this, it became possible to establish the fact that the application of the high-rate vermicomposting concept and the associated know-how enables the vermicomposting of salvinia in a highly efficient and sustainable manner. The results also indicate that if the reactors are operated in a normal pulse-fed fashion, wherein some feed biodegradation will occur naturally as well as earthworms born in the reactors will hasten feed utilization, it may be possible to achieve a near $100 \%$ process efficiency at solid retention times of 15 to 20 days. Given that vermicomposting of phytomass like salvinia in conventional vermicomposting systems requires 3 to 4 months for complete feed conversion - that, too, after pretreatment and liberal supplementation of animal manure - the present process is several times faster, besides being significantly more frugal. 


\section{Competing interests}

The authors declare that they have no competing interests.

\section{Authors' contributions}

All authors have contributed equally. All authors read and approved the final manuscript.

\section{Acknowledgements}

SG, PL and SAA, thank the Department of Biotechnology, Government of India for support. TGK is grateful to the University Grants Commission for Rajiv Gandhi National Fellowship.

Received: 29 July 2014 Accepted: 10 November 2014

Published online: 02 December 2014

\section{References}

1. Abbasi SA, Nipaney PC (1986) Infestation by aquatic weeds of the fern genus Salvinia: its status and control. Environ Conserv 13:235-241

2. Room PM, Thomas PA (1986) Population growth of the floating weed Salvinia molesta: field observation and a global model based on temperature and nitrogen. J Appl Ecol 23(3):1013-1028

3. Abbasi SA, Nipaney PC (1993) World's worst weed (salvinia): its impact and utilization. International book Distributors, Dehradun, p 226

4. Abbasi SA, Nipaney PC (1994) Potential of aquatic weed Salvinia molesta (Mitchell) for water-treatment and energy recovery. Ind J Chem Technol 1(4):204-213

5. Abbasi SA, Nipaney PC (1995) Productivity of aquatic weed salvinia (Salvinia molesta, Mitchell) in natural waters. Ecol Environ Conserv 1(1-4):11-12

6. Abbasi T, Tauseef SM, Abbasi SA (2012) Biogas energy, Springer, New York \& London, xiv+169 Pages; ISBN 978-1-4614-1039-3

7. Abbasi SA, Nipaney PC (1991) Effect of temperature on biogas production from aquatic fern Salvinia. Ind J Technol 29:306-309

8. Abbasi SA, Nipaney PC, Soni R (1988) Aquatic weeds - distribution, impact, and control. J Sci Ind Res 47(11):650-661

9. Abbasi SA, Nipaney PC, Ramasamy EV (1992) Use of aquatic weed salvinia (Salvinia molesta, Mitchell) as full partial feed in commercial biogas digesters. Ind J Technol 30(9):451-457

10. Anuradha J, Abbasi T, Abbasi SA (2014) An eco-friendly method of synthesizing gold nanoparticles using on otherwise worthless weed pistia (Pistia stratiotes L.). J Adv Res, http://dx.doi.org/10.1016/j.jare.2014.03.006.

11. Gajalakshmi S, Ramasamy EV, Abbasi SA (2002) Vermicomposting of different forms of water hyacinth by the earthworm Eudrilus engeniae, Kinberg. Biorescour Technol (Elsevier) 82:165-169

12. Gajalakshmi S, Ganesh PS, Abbasi SA (2005) A highly cost-effective simplification in the design of fast-paced vermireactor. Biochem Eng J (Elsevier) 22:111-116

13. Abbasi T, Gajalakshmi S, Abbasi SA (2009) Towards modeling and design of vermicomposting systems: mechanisms of composting/vermicomposting and their implications. Ind J Biotechnol 8:177-182

14. Ganesh PS, Gajalakshmi S, Abbasi SA (2009) Vermicomposting of the leaf litter of acacia (Acacia auriculiformis): possible roles of reactor geometry, polyphenols, and lignin. Bioresour Technol (Elsevier) 100:1819-1827

15. Abbasi T, Tauseef SM, Abbasi SA (2011) The inclined parallel stack continuously operable vermireactor. Official J Patent Off 22:9571

16. Tauseef SM, Abbasi T, Banupriya D, Vaishnavi V, Abbasi SA (2013a) HEVSPAR: a novel vermireactor system for treating paper waste. Official J Patent Off 24:12726

17. Tauseef SM, Abbasi T, Banupriya G, Banupriya D, Abbasi SA (2013b) A new machine for clean and rapid separation of vermicast, earthworms, and undigested substrate in vermicomposting systems, Journal of Environmental Science and Engineering, communicated.

18. Abbasi SA, Nayeem-Shah M, Abbasi T (2014) Vermicomposting of phytomass: limitations of the past approaches and the promise of the clean and efficient high-rate vermicomposting technology. J Cleaner Product, in press.

19. Nayeem-Shah M (2014) Exploration of methods for gainful utilization of phytomass-based biowaste. PhD Thesis, Pondicherry University. pp. 92.

20. Abbasi T, Tauseef SM, Abbasi SA (2013) Energy recovery from wastewaters with high-rate anaerobic digesters. Renewab Sustain Energ Rev 19:704-741

21. Tauseef SM, Premalatha M, Abbasi T, Abbasi SA (2013) Methane capture from livestock manure. J Environ Manage 117:187-207

22. Gajalakshmi S, Abbasi SA (2004) Earthworms and vermicomposting. Ind J Biotechnol 3:486-494
23. Gajalakshmi S, Abbasi SA (2008) Solid waste management by composting: state of the art. Critic Rev Environ Sci Technol (CRC Press) 38:311-400

24. Edwards CA, Arancon NQ, Sherman R (2011) Vermiculture technology. CRC Press, London, New York. pp. xix+601

25. Gajalakshmi S, Abbasi SA (2003) High-rate vermicomposting systems for recycling paper waste. Ind J Biotechnol 2:613-615

doi:10.1186/s40643-014-0026-4

Cite this article as: Ganeshkumar et al:: A new process for the rapid and direct vermicomposting of the aquatic weed salvinia (Salvinia molesta).

Bioresources and Bioprocessing 2014 1:26.

\section{Submit your manuscript to a SpringerOpen ${ }^{\circ}$ journal and benefit from:}

- Convenient online submission

- Rigorous peer review

- Immediate publication on acceptance

- Open access: articles freely available online

- High visibility within the field

- Retaining the copyright to your article

Submit your next manuscript at $>$ springeropen.com 